\title{
Acculturation and Food Intake Among Ghanaian Migrants in Europe: Findings From the RODAM Study
}

Hibbah Araba Osei-Kwasi, MSc, $\mathrm{PhD}^{1,2}$; Daniel Boateng, MPH, MSc, $\mathrm{PhD}^{3,4}$; Ina Danquah, MSc, $\mathrm{PhD}^{5}$; Michelle Holdsworth, $\mathrm{RD}, \mathrm{PhD}^{1,6}$; Caroline Mejean, $\mathrm{PhD}^{7}$; Laura Terragni, $\mathrm{PhD}^{8}$; Katie Powell, $\mathrm{PhD}^{1}$; Matthias B. Schulze, $\mathrm{DrPH}^{5,9}$; Ellis Owusu-Dabo, MD, $\mathrm{PhD}^{10}$; Karlijn Meeks, MSc, $\mathrm{PhD}^{11}$; Erik Beune, MSc, $\mathrm{PhD}^{11}$; Charles Agyemang, MPH, $\mathrm{PhD}^{11}$; Kerstin Klipstein-Grobusch, MSc, $\mathrm{PhD}^{3,12}$; Karien Stronks, MSc, $\mathrm{PhD}^{11}$; Cecilia Galbete, $\mathrm{PhD}^{5}$; Mary Nicolaou, $\mathrm{PhD}^{11}$

\begin{abstract}
Objective: This study examined the role of migration and acculturation in the diet of Ghanaian migrants in Europe by (1) comparing food intake of Ghanaian migrants in Europe with that of Ghanaians living in Ghana and (2) assessing the association between acculturation and food intake.

Design: Data from the cross-sectional multicenter study Research on Obesity and Diabetes among African Migrants were used. Food intake was assessed using a Ghana-specific food propensity questionnaire (134 items and 14 food groups); foods were grouped based on a model of dietary change proposed by Koctürk-Runefors. Setting: Ghana, London, Amsterdam, and Berlin.

Participants: A total of 4,534 Ghanaian adults living in Ghana and Europe, with complete dietary data. Of these, 1,773 Ghanaian migrants had complete acculturation data.

Main Outcome Measure: Food intake (the weighted intake frequency per week of food categories).

Analysis: Linear regression.

Results: Food intake differed between Ghanaians living in Ghana and Europe. Among Ghanaian migrants in Europe, there were inconsistent and small associations between acculturation and food intake, except for ethnic identity, which was consistently associated with intake only of traditional staples.

Conclusions and Implications: Findings indicate that migration is associated with dietary changes that cannot be fully explained by ethnic, cultural, and social acculturation. The study provides limited support to the differential changes in diet suggested by the Koctürk-Runefors' model of dietary change.

Key Words: acculturation, food intake, Ghanaian migrant, Koctürk-Runefors' model, migration (J Nutr Educ Behav. 2020; 52:114-125.)
\end{abstract}

Accepted September 5, 2019. Published online October 7, 2019.

\footnotetext{
${ }^{1}$ Public Health Section, School of Health and Related Research, University of Sheffield, Sheffield, United Kingdom

${ }^{2}$ Department of Clinical Sciences and Nutrition, University of Chester, Parkgate Road, Tower Building, United Kingdom

${ }^{3}$ Julius, Global Health, Julius Center for Health Sciences and Primary Care, University Medical Center Utrecht, Utrecht University, The Netherlands

${ }^{4}$ School of Public Health, Kwame Nkrumah University of Science and Technology, Kumasi, Ghana

${ }^{5}$ Department of Molecular Epidemiology, German Institute of Human Nutrition Potsdam-Rehbruecke (DIfE), Nuthetal, Germany

${ }^{6}$ Institute of Research for Development, UMR Nutripass IRD, UM, SupAgro, Montpellier, France

${ }^{7}$ MOISA, University of Montpellier, INRA, CIRAD, CIHEAM-IAMM, Montpellier SupAgro, Montpellier, France

${ }^{8}$ Department of Nursing and Health Promotion, Faculty of Health Sciences, OsloMet-Oslo Metropolitan University, Oslo, Norway

${ }^{9}$ Institute of Nutritional Sciences, University of Potsdam, Nuthetal, Germany

${ }^{10}$ Kumasi Centre for Collaborative Research in Tropical Medicine, College of Health Sciences, KNUST, Kumasi, Ghana

${ }^{11}$ Department of Public Health, Amsterdam UMC, University of Amsterdam, Amsterdam Public Health Research Institute, Amsterdam, The Netherlands

${ }^{12}$ Division of Epidemiology and Biostatistics, School of Public Health, Faculty of Health Sciences, University of the Witwatersrand, Johannesburg, South Africa

Conflict of Interest Disclosure: The authors have not stated any conflicts of interest.

Address for correspondence: Hibbah Araba Osei-Kwasi, PhD, Public Health Section, School of Health and Related Research, University of Sheffield, Sheffield, UK Regent Ct, 30 Regent St, Sheffield S1 4DA, UK; E-mail: h.a.osei-kwasi@sheffield.ac.uk

(C) 2019 The Authors. Published by Elsevier Inc. on behalf of Society for Nutrition Education and Behavior. This is an open access article under the CC BY-NC-ND license. (http://creativecommons.org/licenses/by-nc-nd/4.0/)

https://doi.org/10.1016/j.jneb.2019.09.004
} 


\section{INTRODUCTION}

The process of acculturation has been linked to dietary change, referred to as dietary acculturation. ${ }^{1}$ The underlying assumption is that changes in diet might result from different exposures, including social and cultural acculturation. Several studies ${ }^{2-5}$ and systematic reviews ${ }^{6,7}$ explored the association between acculturation and diet, but the influence of acculturation on dietary intake is still not fully understood.

The Koctürk-Runefors model was developed to enhance the understanding of adaptation to new food patterns after migration. ${ }^{8}$ In this model, foods are grouped into 3 categories: staple, complementary, and accessory. The model postulates that there is selective dietary change, in which staple foods may remain important in the diet for several generations because these are strongly tied to cultural identity. Complementary foods are more likely to change, but at a relatively slow rate, whereas accessory foods change quickly because these have a less central role for identity. ${ }^{8}$

There has been little attempt to study dietary change among West African migrants to Europe. In a recent study of Ghanaian migrants, ${ }^{9}$ the authors observed differences in food preferences across study sites in Ghana and Europe. However, the role of acculturation and food intake remains to be investigated. Ghanaians are 1 of the largest West African migrant groups living in Europe. ${ }^{10}$ Evidence shows that there are high risks for obesity and type 2 diabetes among Ghanaian migrants in Europe compared with their compatriots living in Ghana. ${ }^{11}$ Two studies, ${ }^{12,13} 1$ of which was a review, underlined the important role of dietary factors in the obesity epidemic and its prevention. Thus, understanding dietary change and its determinants is highly relevant for this migrant population.

Using the Koctürk-Runefors $\operatorname{model}^{8}$ as a framework, the current study examined the role of migration and acculturation in the diet of Ghanaian migrants in Europe by (1) comparing food intake of Ghanaian migrants in Europe with that of Ghanaians living in Ghana; and (2) assessing the association among ethnic, social, and cultural acculturation with food intake among Ghanaian migrants in Europe.

\section{METHODS}

\section{Study Design and Study Population}

The current analysis used data from the cross-sectional multicenter study Research on Obesity and Diabetes among African Migrants (RODAM), the details of which were published elsewhere, ${ }^{11,14}$ including recruitment procedures, assessment methods, and sample size estimations. Briefly, a representative sample of Ghanaian adults was recruited between 2012 and 2015 in 4 countries: Ghana, the United Kingdom, Germany, and The Netherlands. As a central feature of the RODAM study, a standardized approach was used for recruitment and data collection at all study sites. The RODAM study obtained ethical approval from all study site local ethics committees, and all participants gave informed written consent. ${ }^{11}$

For the current analysis, the number of participants with complete dietary data $(n=4,534)$ for Ghana and Europe was used to explore differences in food intake between geographical locations. Missing data in this study were considered small and nonrandom. Therefore, case mean substitution was used for individual cases that had 1 item missing. ${ }^{15}$ Participants with $\geq 2$ missing values on the items used to assess the proxies of acculturation variables were excluded from analyses to investigate the influence of acculturation on food intake (Supplementary Data).

\section{Assessment of Food Intake}

For dietary assessment, a standardized, semiquantitative, Ghana-specific food propensity questionnaire documented the usual food intake of all participants. The questionnaire was specifically developed for the RODAM study to incorporate typical Ghanaian foods that were identified in the Ghana Demographic and Health Survey $(2008)^{16}$ and in previous Ghanaian migrant studies conducted in Amsterdam. ${ }^{17}$ This questionnaire assessed the intake frequencies of 134 food items in predefined portion sizes during the past 12 months. Foods were categorized according to the model of Koctürk-Runefors. ${ }^{8}$ Food items were collapsed into 14 food groups, which were subsequently categorized as staple, complementary, and accessory foods (Supplementary Data). Food groups consisted of traditional indicator foods such as plantain, roots, and tubers, because the traditional diet in West Africa is characterized by high intakes of plantain and other staples, ${ }^{18,19}$ whereas foods associated with adaptation to the host country included pasta and potatoes.

In food frequency questionnaires, a long list of food items can lead to an overestimation of the true intake of foods and nutrients. ${ }^{20}$ At the same time, measurement error can occur when certain food groups in the list comprise more items than others, such as fruits or vegetables. ${ }^{21}$ Thus, the regression correction method ${ }^{22}$ was applied to assign weights to food groups corresponding to the relative contribution of these groups to the explained variance in food category consumption. In linear regression, $\beta$ coefficients were calculated for the intake frequency of food groups (frequency per week) contributing to a food category. Subsequently, the regression coefficient of a food group was used as the weighting factor for the intake frequency of this food group. To estimate the weighted frequency of intake, the researchers first ran linear regressions with outcomes of frequency per week of food groups and exposures of the summed frequency of food categories. The $\beta$ coefficients from the models represented the extent to which each food category contributed to the food groups (staple, complementary, and accessory foods). The weighted intake of each food category equaled the summed intake of the food category multiplied by the $\beta$ coefficient of the food category.

As the basis for understanding dietary changes upon migration, food intake and consumption (ie, the weighted intake frequency per week of food categories) among Ghanaian migrants in Europe were compared with that of their compatriots living in Ghana (adjusted for age and sex). 


\section{Assessment of Acculturation}

Assessment of acculturation was operationalized using 2 methods. First, the researchers measured acculturation using 26 items based on ethnic identity (ethnic acculturation), social networks (social acculturation), and cultural orientation (cultural acculturation). ${ }^{23,24}$ These 3 constructs included questions regarding how participants felt about their identity, having friends from the host country, and spending time within a social network of the host country or commonalities with the host culture. Berry's ${ }^{25}$ bidimensional perspective of acculturation was used to operationalize answers to these questions, which were grouped into 4 domains: integration, assimilation, separation, and marginalization. When a group has an interest in maintaining its culture while trying to adopt some cultural aspects of a new society, it is described as integration. Assimilation is when a group or individuals adopt the culture of the new society without maintaining their cultural identity. When individuals do not want to maintain their traditional culture or adopt that of the new society, it is described as marginalization. Finally, separation occurs when individuals hold on to their original culture and avoid interaction with others. ${ }^{4}$ For ethnic identity, 2 questions on how participants felt about their identity were rated on a 5-point scale. Social network was assessed with 4 items. A mean score was calculated of the 2 items of having friends from the host country and spending time within a social network of the host country. This was also performed for the social network of the country of origin. Cultural orientation was assessed using 20 items, and asked participants to what extent they agreed with 10 statements regarding the host culture. All questions used for the assessment and the details of the scoring are presented as Supplementary Data. However, Berry's bidimensional perspective revealed a skewed distribution of acculturation in the different groups. As a consequence, participants were classified into 2 groups for the main analyses presented here: more acculturated (integrated plus assimilated) and less acculturated (separated plus marginalized).
In the second operationalization of acculturation, predefined unidimensional proxies (eg, duration of residence) were applied that reflected exposure to the host culture. For the duration of residence, more years spent in Europe was used to indicate greater exposure to the host culture; this was classified into the categories of $\leq 10$ years, $11-20$ years, and $>20$ years. ${ }^{26}$

\section{Assessment of Socioeconomic and Demographic Variables}

Socioeconomic and demographic variables are known to be possible confounders in the association between acculturation and $\operatorname{diet}^{5}$; therefore, education, age (in years), body mass index (BMI) (in $\mathrm{kg} / \mathrm{m}^{2}$ ), and sex variables were included in the analyses, as shown in Table 1. Assessment and categorization of these variables are described in detail elsewhere. ${ }^{11,14}$

\section{Statistical Analysis}

Data analyses were conducted using the statistical software package IBM SPSS Statistics (Version 23.0, SPSS, Inc, Armonk, NY, 2013). Sociodemographic, anthropometric, and acculturation characteristics are presented as mean $( \pm \mathrm{SD})$ for continuous variables; categorical variables are presented as percentages. Characteristics were compared between participants living in Ghana and Europe by t test for continuous variables and by chisquare test of independence for categorical data.

Linear regression models were used to determine the independent effects of ethnic identity, social networks, cultural orientation (all 3 variables were dichotomized as described earlier), and duration of residence on weighted food intakes of individual food groups within each food category. Unstandardized $\beta$ coefficients and corresponding 95\% confidence intervals (CIs) were reported for the mean difference in weighted food intake between the more and less acculturated Ghanaian migrants in Europe. The model was further adjusted for age, sex, education, the country in Europe, educational level, and interaction (country $\times$ acculturation). Because previous work on the RODAM project ${ }^{9}$ showed no differences between men and women regarding exposure and outcome variables, data for men and women were combined. Because BMI is a potential mediator in the association between acculturation and dietary intake, the researchers first ran models without including BMI; results indicated that adding this variable did not substantially alter the findings. Therefore, BMI was included in the final model. All $P$ values reported are 2 tailed; values $<.05$ were considered statistically significant. $P<.10$ was considered statistically significant for the interaction terms.

\section{RESULTS}

\section{General Characteristics of Study Population}

Table 1 shows characteristics of the study participants stratified by whether they lived in Ghana or Europe. Of the 4,543 participants with complete dietary data in Ghana and Europe, $43.8 \%$ of Ghanaian migrants were men, compared with $33.3 \%$ of Ghanaians living in Ghana. Mean (SD) age was 46.4 (10.3) years for Europe and 46.7 (12.9) years for Ghana. About $14.6 \%$ of Ghanaian migrants had a higher vocational or university education, whereas the percentage for Ghanaians living in Ghana with a higher vocational or university education was $4.3 \%$. With regard to BMI, $34.5 \%$ of participants in Europe were obese, compared with $16.8 \%$ in Ghana.

Regarding the level of acculturation of participants, mean length of stay in Europe was 16.9 (9.7) years, and $36.5 \%$ of Ghanaian migrants had lived in Europe for $>20$ years. Over half of Ghanaian migrants were classified as integrated based on 3 proxies of acculturation: ethnic (57.1\%), social $(55.5 \%)$, and cultural (73.6\%). For ethnic acculturation, $41 \%$ of participants were classified as separated.

\section{Differences in Food Intake \\ Between Ghanaian Migrants in Europe and Ghanaians Living in Ghana}

The Figure presents differences in the weighted intake frequency per week of food groups within the 3 food categories between Ghanaians 


\section{Table 1. Sociodemographic and Anthropometric Parameters and Proxies of Acculturation Data for Ghanaians} Living in Europe $(n=2,011)$ and in Ghana $(n=2,543)$

\section{Variables}

$\mathrm{n}(\%)$

Sex (male) $(\%)$

Age, y (mean \pm SD)

Completed education (\%)

Higher vocational schooling or university

Intermediate vocational or higher secondary schooling (general)

Lower vocational schooling or lower secondary schooling

Never been to school or elementary schooling only

BMI, $\mathrm{kg} / \mathrm{m}^{2}(\%)^{\mathrm{c}}$

$<25$

25-29.9

$\geq 30$

Proxies of acculturation

Ethnic identity (\%)

Less acculturated

More acculturated

Berry's acculturation strategy

Integration

Assimilation

Separation

Marginalization

Social network (\%)

Less acculturated

More acculturated

Berry's acculturation strategy

Integration

Assimilation

Separation

Marginalization

Cultural orientation (\%)

Less acculturated

More acculturated

Berry's acculturation strategy

Integration

Assimilation

Separation

Marginalization

Duration of residence, y (\%)

$<10$

$11-20$

$\geq 20$
Ghanaian Migrants in Europe

$2,011(44.3)^{2}$

43.8

$46.4 \pm 10.3$

14.6

24.5

39.5

21.4

22.3

43.2

34.5

41.6

58.4

57.1

1.3

41.0

0.6

27.8

72.2

55.5

16.7

16.8

11.0

26.2

73.8

73.6

0.2

25.9

0.3

25.9

28.7

36.5

BMI indicates body mass index.

${ }^{a}$ Amsterdam (48.4\%), Berlin (28.0\%), London (23.5\%), urban; ${ }^{b}$ Ghana $(56.4 \%)$, rural Ghana $(43.6 \%)$; ${ }^{\circ}$ Categorized per World Health Organization standards; ${ }^{\mathrm{d}} P$ calculated with chi-square test of independence; ${ }^{\mathrm{e}} P$ calculated with 1-way ANOVA.

living in Europe and Ghana. Among Ghanaians living in Ghana, plantain, roots, and tubers contributed $48 \%$ to the intake of staples, whereas pasta and potatoes contributed
5\%. Among Ghanaian migrants in Europe, bread and cereals contributed $47 \%$ to the intake of staples, whereas plantain, roots, and tubers contributed $22 \%$.
Ghanaians Living in Ghana $2,532(55.7)^{b}$ 33.3

$46.7 \pm 12.9$
4.3

10.2

35.4

37.2

50.1

37.3

56.4

41.3

26.8

34.1

24.6

8.9

6.6

16.8
$<.001$

\section{$\boldsymbol{P}$}

$<.001^{\mathrm{d}}$

$<.001^{\circ}$

$<.001^{d}$

$<.001$

. 


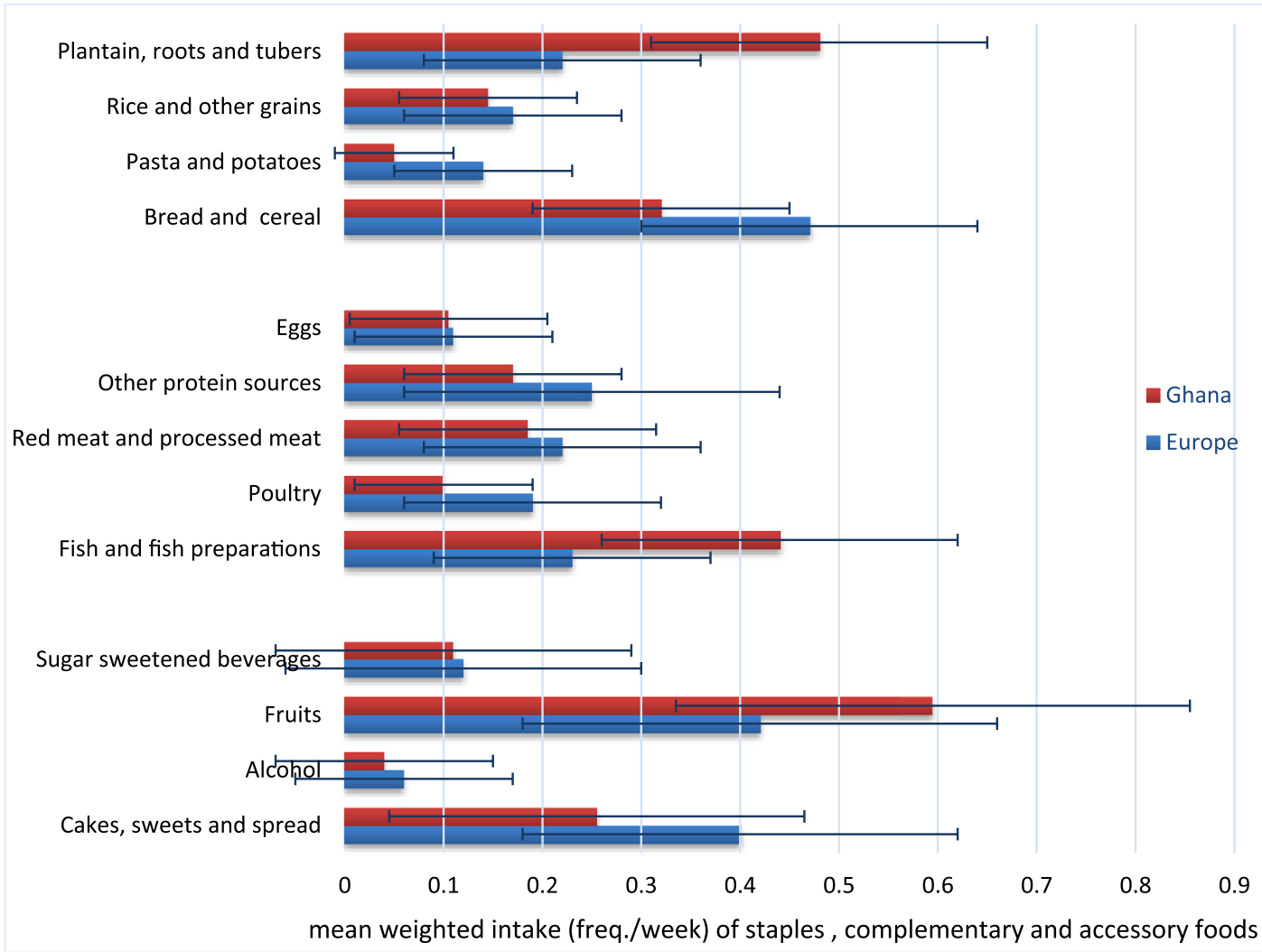

Figure. Mean weighted frequency of intake for Ghanaian migrants in Europe and Ghanaians living in Ghana, adjusted by age and gender.

migrants in Europe consumed 25\% of complementary foods as other sources of protein (milk, cheese, and yogurt; and legumes, beans, seeds), 22\% as red and processed meat, and $19 \%$ as poultry. Fruit intake contributed 58\% to accessory food intake among Ghanaians living in Ghana, and 42\% among Ghanaian migrants in Europe. Cakes, sweets, and spreads contributed $40 \%$ to accessory food intake among Ghanaian migrants compared with 26\% among Ghanaians living in Ghana. No interaction was observed between acculturation and European country of residence for the intake of most food categories.

Table 2 presents differences in the weighted intake of staple, accessory, and complementary foods between more and less acculturated Ghanaian migrants, using ethnic identity, social network, cultural orientation, and length of stay in Europe as proxies of acculturation. Among staple foods, the mean weighted frequency of intake of plantain, roots, and tubers was significantly higher among participants who were less acculturated, than in those who were more acculturated, based on ethnic identity $(P=.01)$, whereas the weighted intake of pasta and potatoes was higher among the more acculturated group $(P=.007)$. The weighted intake of rice and other grains was also significantly higher among the less acculturated participants when social network $(P=.007)$ was used as a measure of acculturation. The weighted intakes of bread and cereals $(P=.007)$ and pasta and potatoes $(P=.02)$ were higher, whereas weighted intakes of rice and other grains $(P<.001)$ were lower for duration of residence $>20$ years.

Within the accessory food category, intake of nonalcoholic beverages was higher among more acculturated participants when using cultural orientation $(P=.03)$, but lower for duration of residence $>20$ years in Europe $(P<.001)$. For complementary foods, there was a higher intake of vegetable stews and soups $(P=.01)$ and a lower intake of other sources of protein $(P=.01)$ among more acculturated Ghanaian migrants based on cultural orientation. The weighted intake of complementary foods was also associated with duration of residence in Europe, with a higher intake of other sources of protein among duration of residence $>20$ years $(P<.001)$.

\section{Associations Between Acculturation and Food Intake Across Europe}

Table 3 shows the association between the more and less acculturated Ghanaian migrants in Europe (using the different proxies of acculturation) and staple foods. The weighted intakes of plantain, roots, and tubers were significantly lower than that of other staples among the more acculturated compared with the less acculturated participants, based on ethnic identity ( $\beta=-0.04 ; 95 \%$ CI, -0.06 to -0.01 ; $P=.01)$. The consumption of these staple foods was relatively higher among more acculturated than in less acculturated participants, based on social network $(P=.81)$ and cultural 


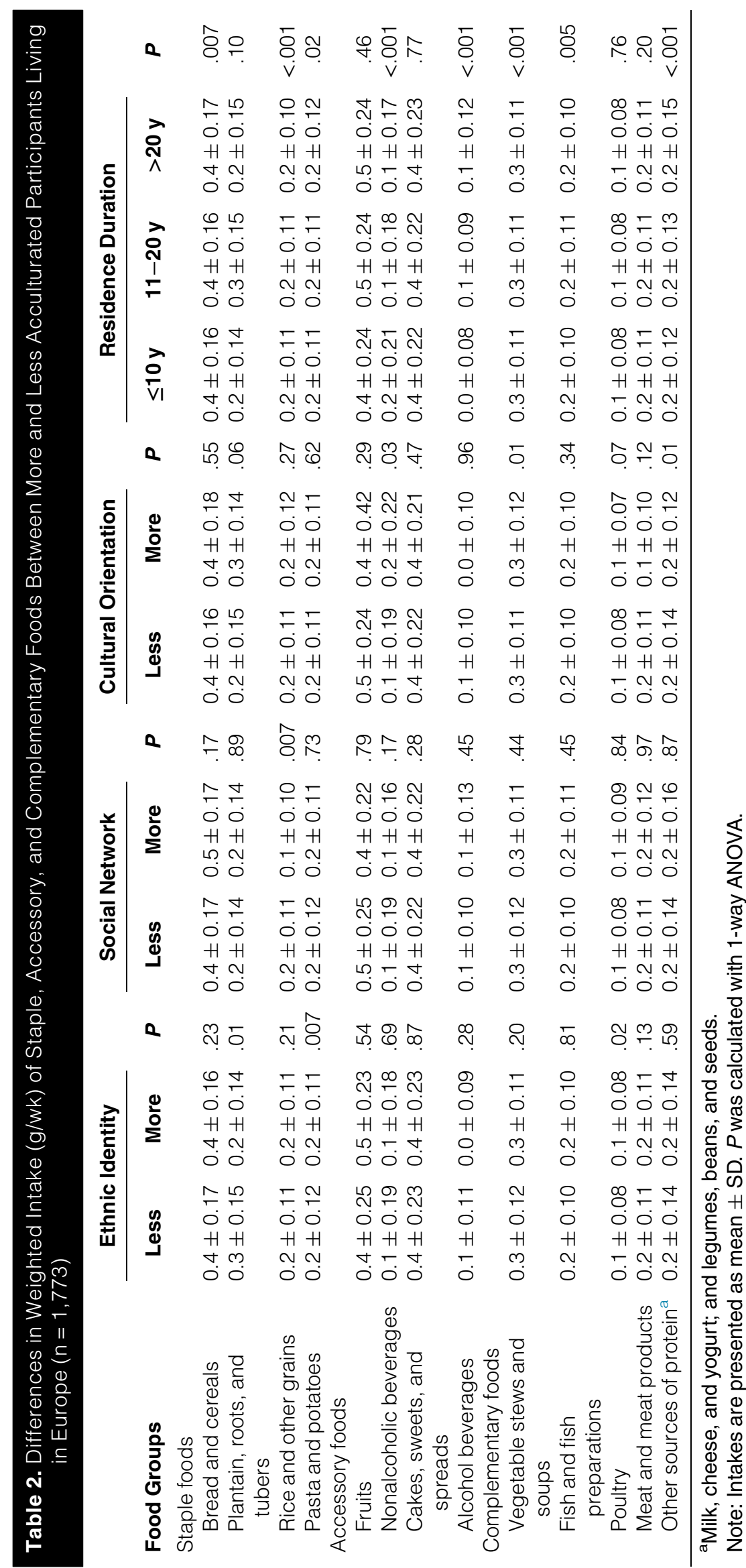

orientation $(P=.25)$, although these associations were not statistically significant. Compared with less acculturated participants (based on cultural orientation), the weighted intake of bread and cereals was .11 frequency/wk lower among more acculturated participants $(\beta=-0.11 ; 95 \% \mathrm{CI},-0.20$ to $-0.01 ; P=.03)$, whereas the weighted intake of bread and cereals was 0.03 frequency/wk higher for the duration of residence of $>20$ years than that in Europe for the duration of residence of $<10$ years $(\beta=0.03$; 95\% CI, 0.01 to $0.05 ; P=.003)$. As with staple consumption, there were specific independent effects of some proxies of acculturation on intakes of complementary foods (Table 4). For instance, longer duration of residence in Europe (>20 years) was associated with lower intake of vegetable stews and soups than in those with duration of residence $<10$ years $(\beta=-0.07 ; \mathrm{CI},-0.10$ to $-0.04 ; P<.001)$. On the contrary, more acculturated participants had a higher weighted intake of vegetable stews and soups than less acculturated participants $(\beta=0.03 ; 95 \% \mathrm{CI}, 0.0$ to $0.06 ; P=.04)$ when social network was used as a proxy of acculturation. There were also significantly higher intakes of other sources of protein (milk, cheese, and yogurt; and legumes, beans, and seeds) among participants with duration of residence $>20$ years than in those with duration of residence $<10$ years $(\beta=0.05 ; 95 \% \mathrm{CI}$, 0.01 to $0.08 ; P=.02)$, as well as the more acculturated participants based on cultural orientation ( $\beta=0.05 ; 95 \%$ CI, 0.02 to $0.09 ; P=.005)$.

Compared with the duration of residence of $\leq 10$ years, fruit consumption was relatively lower than for other accessory foods for a duration of residence of $10-20$ years $(\beta=-0.08 ; 95 \% \mathrm{CI},-0.15$ to -0.01 ; $P=.02$ ) (Table 5). Consumption of cakes, sweets, and spreads was relatively higher among duration of residence of $>20$ years $(\beta=0.08$; 95\% CI, 0.02 to $0.14 ; P=.007)$ than in $\leq 10$ years' stay in Europe. Alcoholic beverage intake was higher than intake of other accessory foods for participants with duration of residence in Europe $>20$ years $(\beta=0.02 ; 95 \% \mathrm{CI}$, $0.02 ; 0.01,0.04 ; P<.001)$ than in those with duration of residence of $<10$ years in Europe. However, the 
Table 3. Beta Coefficients and $95 \% \mathrm{Cls}$ for Differences in Weighted Intake of Staple Foods Between More and Less Acculturated Ghanaians Living in Europe

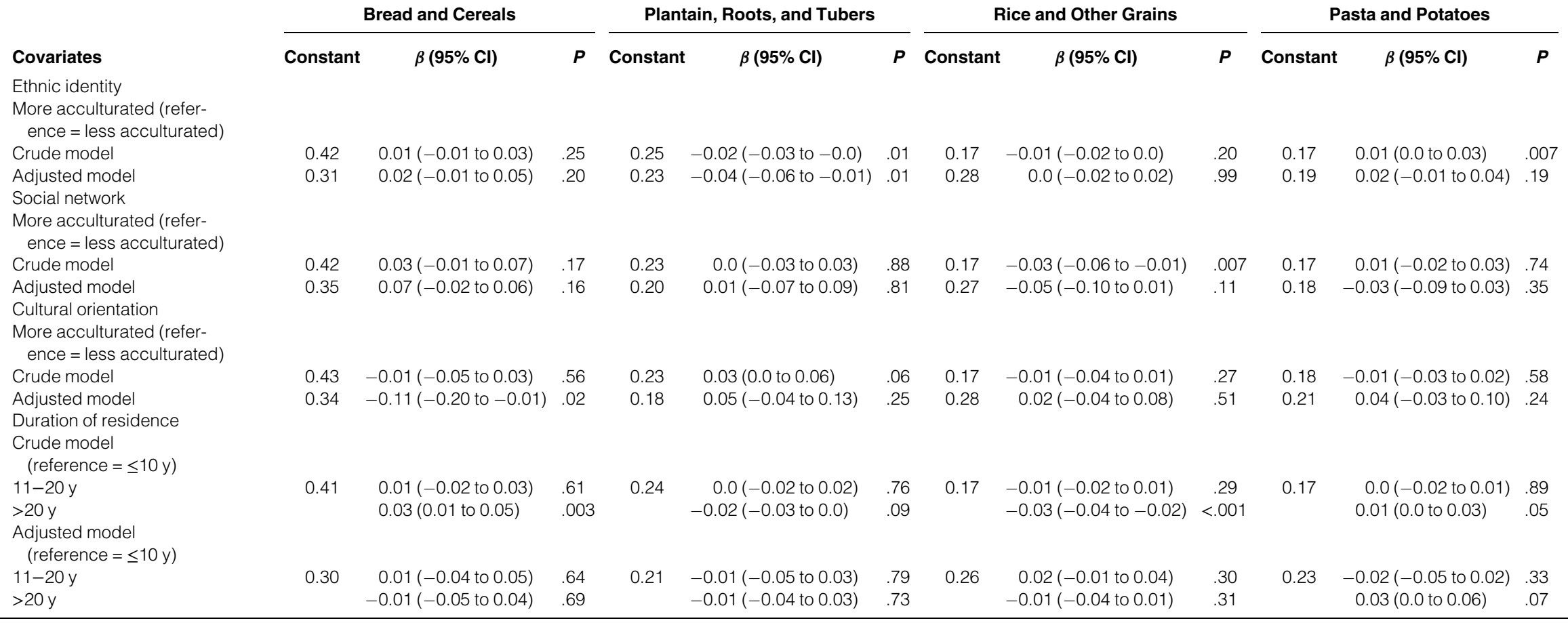

$\mathrm{Cl}$ indicates confidence interval.

Notes: Unstandardized regression $\beta$ coefficients were used to determine mean differences in weighted food intake. The statistical test was linear regression. The model was adjusted for age, sex, site, education, body mass index, and interaction terms (ethnic identity $\times$ site, social network $\times$ site, and cultural orientation $\times$ site). 
Table 4. Beta Coefficients and $95 \%$ Cls for Differences in Weighted Intake of Complementary Foods Between More and Less Acculturated Ghanaians in Europe

\begin{tabular}{|c|c|c|c|c|c|c|c|c|c|c|c|c|c|c|c|}
\hline \multirow[b]{2}{*}{ Covariates } & \multicolumn{3}{|c|}{$\begin{array}{l}\text { Vegetable Stews } \\
\text { and Soups }\end{array}$} & \multicolumn{3}{|c|}{$\begin{array}{c}\text { Fish and } \\
\text { Fish Preparations }\end{array}$} & \multicolumn{3}{|c|}{ Poultry } & \multicolumn{3}{|c|}{$\begin{array}{c}\text { Meat and } \\
\text { Meat Products }\end{array}$} & \multicolumn{3}{|c|}{$\begin{array}{l}\text { Other Sources } \\
\text { of Protein" }\end{array}$} \\
\hline & Constant & $\beta(95 \% \mathrm{Cl})$ & $P$ & Constant & $\beta(95 \% \mathrm{Cl})$ & $P$ & Constant & $\beta(95 \% \mathrm{Cl})$ & $P$ & Constant & $\beta(95 \% \mathrm{Cl})$ & $P$ & Constant & $\beta(95 \% \mathrm{Cl})$ & $P$ \\
\hline $\begin{array}{l}\text { Ethnic identity } \\
\text { More acculturated } \\
\text { (reference = less } \\
\text { acculturated) }\end{array}$ & & & & & & & & & & & & & & & \\
\hline Crude model & 0.27 & $0.01(-0.02$ to 0.0$)$ & .21 & 0.18 & 0.0 ( -0.01 to 0.01$)$ & .67 & 0.13 & $-0.01(-0.02$ to -0.0$)$ & .03 & 0.15 & $0.01(-0.01$ to 0.02$)$ & .10 & 0.19 & $0.0(-0.01$ to 0.02$)$ & .65 \\
\hline $\begin{array}{l}\text { Adjusted model } \\
\text { Social networks } \\
\text { More acculturated } \\
(\text { reference }=\text { less } \\
\text { acculturated })\end{array}$ & 0.26 & $-0.02(-0.04$ to 0.0$)$ & .08 & 0.14 & $-0.01(-0.03$ to 0.01$)$ & .51 & 0.14 & $0.0(-0.02$ to 0.01$)$ & .79 & 0.21 & $0.01(-0.01$ to 0.03$)$ & .46 & 0.11 & $0.01(-0.01$ to 0.04$)$ & .34 \\
\hline Crude model & 0.26 & $0.01(-0.01$ to 0.02$)$ & .41 & 0.18 & $0.0(-0.01$ to 0.01$)$ & .74 & 0.13 & $-0.01(-0.01$ to 0.0$)$ & .27 & 0.16 & 0.0 (-0.01 to 0.01$)$ & .84 & 0.19 & 0.0 (-0.01 to 0.02$)$ & .88 \\
\hline $\begin{array}{l}\text { Adjusted model } \\
\text { Cultural orientation } \\
\text { More acculturated } \\
\text { (reference = less } \\
\text { acculturated) }\end{array}$ & 0.23 & 0.03 (0.0 to 0.06$)$ & .04 & 0.14 & $0.0(-0.03$ to 0.02$)$ & .82 & 0.15 & $-0.01(-0.03$ to 0.01$)$ & .27 & 0.22 & 0.0 (-0.03 to 0.02$)$ & .97 & 0.13 & $-0.02(-0.05$ to 0.02$)$ & .36 \\
\hline $\begin{array}{l}\text { Crude model } \\
\text { Adjusted model } \\
\text { Duration of residence } \\
\text { Crude model } \\
\text { (reference }=\leq 10 \mathrm{y} \text { ) }\end{array}$ & $\begin{array}{l}0.29 \\
0.28\end{array}$ & $\begin{array}{l}-0.03(-0.05 \text { to }-0.01) \\
-0.05(-0.07 \text { to }-0.02)\end{array}$ & $\begin{array}{l}.002 \\
.002\end{array}$ & $\begin{array}{l}0.20 \\
0.16\end{array}$ & $\begin{array}{l}-0.02(-0.04 \text { to } 0.0) \\
-0.03(-0.05 \text { to } 0.0)\end{array}$ & $\begin{array}{l}.03 \\
.04\end{array}$ & $\begin{array}{l}0.14 \\
0.12\end{array}$ & $\begin{array}{l}-0.02(-0.03 \text { to } 0.0) \\
0.01(-0.01 \text { to } 0.04)\end{array}$ & $\begin{array}{l}.04 \\
.22\end{array}$ & $\begin{array}{l}0.14 \\
0.21\end{array}$ & $\begin{array}{l}0.02(0.0 \text { to } 0.04) \\
0.02(-0.01 \text { to } 0.05)\end{array}$ & $\begin{array}{l}.02 \\
.11\end{array}$ & $\begin{array}{l}0.15 \\
0.07\end{array}$ & $\begin{array}{l}0.05 \text { (0.02 to } 0.07) \\
0.05 \text { (0.02 to } 0.09)\end{array}$ & $\begin{array}{r}<.001 \\
.005\end{array}$ \\
\hline $\begin{array}{l}11-20 y \\
>20 y \\
\text { Adjusted model } \\
\quad(\text { reference }=\leq 10 y)\end{array}$ & 0.27 & $\begin{array}{c}0.0(-0.01 \text { to } 0.02) \\
-0.03(-0.04 \text { to }-0.01)\end{array}$ & $\begin{array}{c}.57 \\
<.001\end{array}$ & 0.17 & $\begin{array}{l}0.02 \text { (0.01 to } 0.03) \\
0.01(-0.01 \text { to } 0.02)\end{array}$ & $\begin{array}{l}.002 \\
.34\end{array}$ & 0.13 & $\begin{array}{l}0.0(-0.01 \text { to } 0.01) \\
0.0(-0.01 \text { to } 0.01)\end{array}$ & $\begin{array}{l}.81 \\
.51\end{array}$ & 0.17 & $\begin{array}{l}-0.01(-0.03 \text { to } 0.0) \\
-0.01(-0.02 \text { to } 0.01)\end{array}$ & $\begin{array}{l}.08 \\
.42\end{array}$ & 0.18 & $\begin{array}{c}-0.01(-0.02 \text { to } 0.01) \\
0.04(0.02 \text { to } 0.06)\end{array}$ & $\begin{array}{c}.45 \\
<.001\end{array}$ \\
\hline $\begin{array}{l}11-20 y \\
>20 y\end{array}$ & 0.25 & $\begin{array}{l}-0.03(-0.06 \text { to } 0.0) \\
-0.07(-0.10 \text { to }-0.04)\end{array}$ & $\begin{array}{r}.007 \\
<.001\end{array}$ & 0.13 & $\begin{array}{r}0.01(-0.01 \text { to } 0.04) \\
0.0(-0.02 \text { to } 0.04)\end{array}$ & $\begin{array}{l}.31 \\
.39\end{array}$ & 0.12 & $\begin{array}{l}0.02(-0.01 \text { to } 0.04) \\
0.02(-0.01 \text { to } 0.04)\end{array}$ & $\begin{array}{l}.14 \\
.13\end{array}$ & 0.23 & $\begin{array}{l}-0.01(-0.04 \text { to } 0.02) \\
-0.01(-0.03 \text { to } 0.02)\end{array}$ & $\begin{array}{l}.42 \\
.67\end{array}$ & 0.13 & $\begin{array}{c}-0.02(-0.05 \text { to } 0.02) \\
0.05(0.01 \text { to } 0.08)\end{array}$ & $\begin{array}{l}.94 \\
.02\end{array}$ \\
\hline
\end{tabular}

Cl indicates confidence interval.

Notes: Unstandardized regression $\beta$ coefficients were used to determine mean differences in weighted food intake. The statistical test was linear regression. The model was adjusted for age, sex, site, education, body mass index, and interaction terms (ethnic identity $\times$ site, social network $\times$ site, and cultural orientation $\times$ site). 
Table 5. Beta Coefficients and 95\% Cls for Differences in Weighted Intake of Accessory Foods Between More and Less Acculturated Ghanaians in Europe

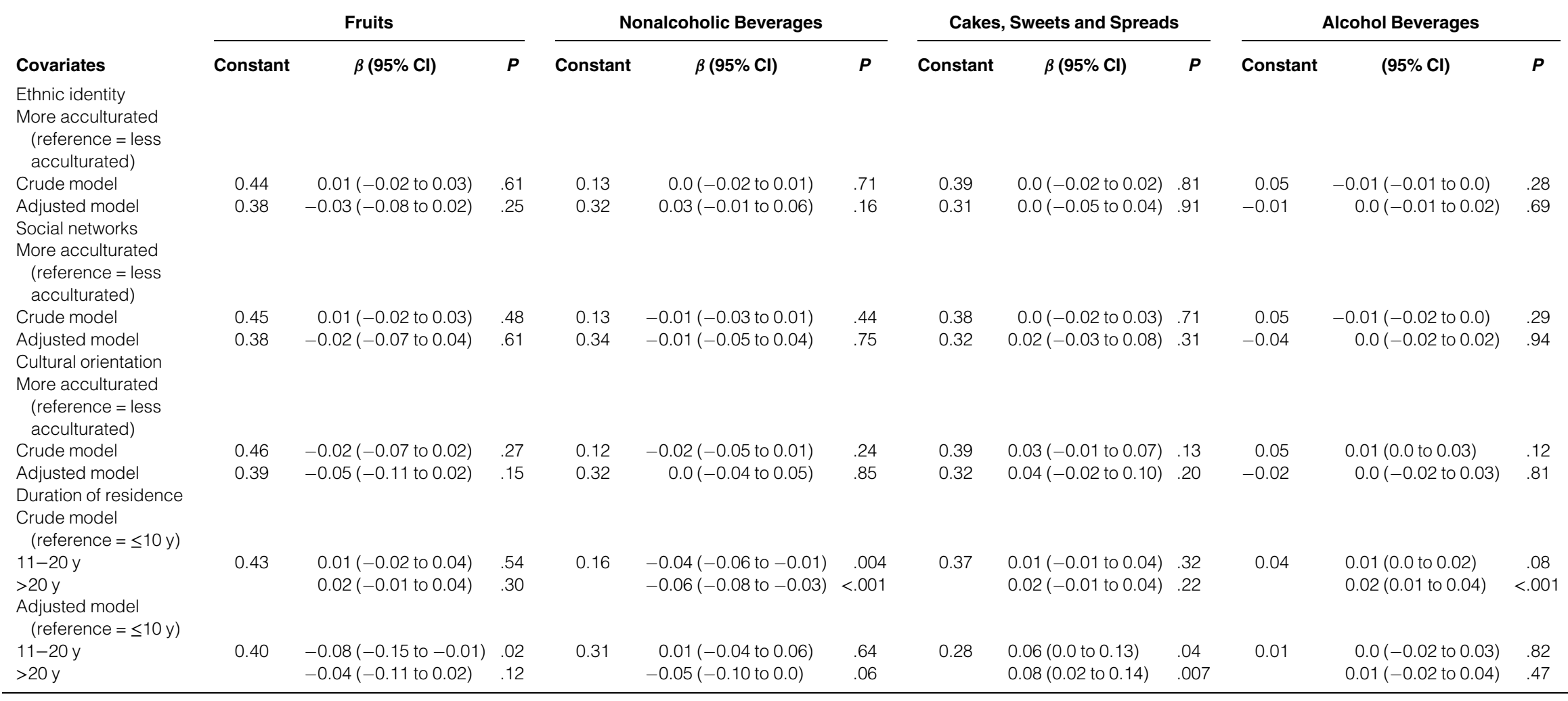

$\mathrm{Cl}$ indicates confidence interval.

Notes: Unstandardized regression $\beta$ coefficients were used to determine mean differences in weighted food intake. The statistical test was linear regression. The model was adjusted for age, sex, site, education, body mass index, and interaction terms (ethnic identity $\times$ site, social network $\times$ site, and cultural orientation $\times$ site). 
effect was attenuated in the adjusted model $(P=.47)$.

\section{DISCUSSION}

This study examined the role of migration and acculturation in the diet of Ghanaian migrants in Europe. Clear differences in food intake were observed between Ghanaians living in Ghana and Europe. However, most associations found between acculturation and food intake among Ghanaian migrants were small, and specific independent effects were observed on food intake for different dimensions of acculturation.

\section{Evidence for Dietary Change With Migration}

Findings of this study are consistent with previous studies that showed traditional staples of migrants remained important components of their diets. ${ }^{3,4}$ However, findings in this study indicated that although plantain, roots, and tubers were still consumed in Europe, bread and cereals were the most important sources of staples, contributing to almost half of the total staple intake of Ghanaian migrants in Europe. Similar to a qualitative study ${ }^{27}$ conducted among Ghanaian migrants in Berlin, this study also demonstrated a shift from a fish-based diet in Ghana to a more meat-based one in Europe. Differences in the intake of accessory foods between Ghana and Europe also provide evidence for the adoption of a more westernized diet after migration, as expected based on the literature on dietary acculturation. ${ }^{28}$

\section{Acculturation, Food Intake, and Koctürk-Runefors Model}

Assessment of acculturation level using all proxies in this study showed that most Ghanaian migrants were integrated. However, with regard to the construct of ethnic identity, many participants were classified as separated, indicating that a large proportion of Ghanaian migrants perceived themselves as being more Ghanaian than European. Combining the integrated and separated groups suggests that $>90 \%$ of Ghanaian migrants had a strong sense of Ghanaian identity. This strong sense of ethnic identity corroborates findings from previous studies among different migrant groups. ${ }^{29-34}$

\section{Differences in food intake between Ghanaians living in Ghana and Ghanaian migrants in Europe may imply dietary change with migration.}

Several studies ${ }^{3,35,36}$ showed consistent associations between acculturation and diet irrespective of the acculturation strategy used. However, a key finding from this study is that associations between acculturation and dietary intake differed according to the acculturation proxy that was applied. Ethnic identity was most consistently associated with the intake of staples, as expected based on the Koctürk-Runefors model. ${ }^{8}$ The importance of identity in dietary choices and the role of food culture as affirmation for the identity of migrants were shown in previous studies. ${ }^{29-32}$

Inconsistencies in the association between acculturation and food intake are attributed to several issues, including methodological considerations, such as variations in the way food intake and acculturation are assessed and its conceptualization. ${ }^{37}$ For example, studies commonly analyze the difference in intakes of specific food groups or nutrients without differentiating among traditional foods within these food groups. The latter approach, as used in this study, may be useful in furthering an understanding of dietary change because of migration and acculturation.

Findings from this study are consistent with those of previous studies ${ }^{2}$ demonstrating that duration of residence was associated with the intake of traditional foods, but contrast studies showed that older migrants were more likely to maintain intake of traditional foods. ${ }^{25}$

This study gave limited support to differential changes in diet suggested by Koctürk-Runefors. ${ }^{8}$ However, differences observed in the intake of food groups within the 3 food categories between Ghanaian migrants in Europe and those living in Ghana suggested dietary acculturation, as shown in previous studies. $^{38-40}$

Given that the Ghanaian migrants in Europe were residing in cities, combining data from rural and urban Ghana was a weakness of this study. Analysis from this study focusing on nutrition transition, presented elsewhere, ${ }^{9,41}$ showed a shift in dietary intake from traditional to westernized diets from rural to urban Ghana, indicating the presence of the nutrition transition.

\section{This study gives limited support to the expected changes in diet suggested by Koctürk- Runefors' model of dietary change.}

Major dietary changes were shown to occur in recent migrants. ${ }^{42} \mathrm{How}$ ever, most migrants in this sample were long-term migrants, ${ }^{26}$ which suggests that they underwent significant acculturation based on the duration of residence in Europe. ${ }^{43}$

Although the term Europe is used throughout this article, including the title, the sample from Europe was taken from 3 northern European cities that were approximately similar regarding the demographics and population size of Ghanaians living there. In considering these findings, it is important to be mindful of this limitation, because food available in the other parts of Europe may differ. Finally, this was a cross-sectional study; as such, it is not suitable to capture the dynamic process of cultural and dietary change. ${ }^{29,30}$

A major strength of this study is the inclusion of Ghanaians living in Ghana, to disentangle the effect of acculturation. The comparison using weighted intake frequencies also provided insight into the relative contributions and the replacement of foods after migration.

\section{IMPLICATIONS FOR RESEARCH AND PRACTICE}

The focus on acculturation as a determinant of diet in this study implies a form of personal choice 
related to food intake. However, previous studies ${ }^{34,44,45}$ showed that the availability of reasonably priced ethnic food ingredients enables migrants to create and maintain their own food culture. This suggests that further research is needed to explore contextual aspects related to the physical food environment in the host country, such as availability, accessibility, and acceptability of foods and the interrelations among these factors, possibly through a systems-based approach. $^{46,47}$

Consistent with Koctürk-Runefors theory, ${ }^{8}$ this study showed that migrants frequently consume traditional staples. This implies that health promotion strategies could be tailored to ethnic identity, because migrants may be more receptive to messages that speak to their ethnocultural identity. ${ }^{38}$ Furthermore, messages could emphasize the reduction of unhealthy accessory foods such as sugar-sweetened beverages, because these foods are presumably less important to identity. Nutrition counseling and interventions could focus on maintaining healthy traditional staples as part of a healthy diet, because this population may be more receptive to messages that emphasize cultural identity.

Nutrition interventions
could focus on
maintaining healthy
traditional staples as part
of healthy meals.

\section{ACKNOWLEDGMENTS}

The RODAM study was supported by the European Commission under the Framework Programme (grant no. 278901). This article was also supported by the Determinants of Diet and Physical knowledge hub, which is supported by the Joint Programming Initiative Healthy Diet for a Healthy Life. The funding agencies supporting this work are France: Institut National de la Recherche Agronomique; Norway: Research Council of Norway; The Netherlands: The Netherlands Organization for Health Research and Development (ZonMw); and the United Kingdom: Medical Research
Council. The authors are grateful to the advisory board members for their valuable support in shaping the methods and the manuscript; to the research assistants, interviewers, and other staff of the 5 research locations who have taken part in gathering the data; and most of all, to the Ghanaian volunteers participating in this project.

\section{SUPPLEMENTARY DATA}

Supplementary data related to this article can be found at https://doi. org/10.1016/j.jneb.2019.09.004.

\section{REFERENCES}

1. Satia-Abouta J, Patterson RE, Neuhouser ML, Elder J. Dietary acculturation: applications to nutrition research and dietetics. J Am Diet Assoc. 2002;102: 1105-1118.

2. Pan YL, Dixon Z, Himburg S, Huffman F. Asian students change their eating patterns after living in the United States. J Am Diet Assoc. 1999;99:54-57.

3. Raza Q, Nicolaou M, Snijder MB, Stronks K, Seidell JC. Dietary acculturation among the South-Asian Surinamese population in the Netherlands: the HELIUS study. Public Health Nutr. 2017;20:1983-1992.

4. Sturkenboom SM, Dekker LH, Lamkaddem M, et al. Acculturation and dietary patterns among residents of Surinamese origin in the Netherlands: the HELIUS dietary pattern study. Public Health Nutr. 2016;19:682-692.

5. Satia JA, Patterson RE, Kristal AR, Hislop TG, Yasui Y, Taylor VM. Development of scales to measure dietary acculturation among Chinese-Americans and Chinese-Canadians. J Am Diet Assoc. 2001;101:548-553.

6. Ayala GX, Baquero B, Klinger S. A systematic review of the relationship between acculturation and diet among Latinos in the United States: implications for future research. $J$ Am Diet Assoc. 2008;108:1330-1344.

7. Pérez-Escamilla R. Acculturation, nutrition, and health disparities in Latinos. Am J Clin Nutr. 2011;93:1163S1167S.

8. Koctürk-Runefors T. A model for adaptation to a new food pattern: the case of immigrants. In: Fürst E, ed. Palatable Worlds: Sociocultural Food Studies.
Oslo, Norway: Solum Forlag; 1991:185-192.

9. Galbete C, Nicolaou M, Meeks KA, et al. Food consumption, nutrient intake, and dietary patterns in Ghanaian migrants in Europe and their compatriots in Ghana. Food Nutr Res. 2017;61:1341809.

10. Twum-Baah A. Volume and characteristics of international Ghanaian migration. In: Manuh T, ed. At Home in the World? International Migration and Development in Contemporary Ghana and West Africa. Accra, Ghana: Sub-Saharan Africa Press; 2005.

11. Agyemang C, Meeks K, Beune E, et al. Obesity and type 2 diabetes in subSaharan Africans-is the burden in today's Africa similar to African migrants in Europe? The RODAM study. BMC Med. 2016;14:166.

12. Landman J, Cruickshank JK. A review of ethnicity, health and nutritionrelated diseases in relation to migration in the United Kingdom. Public Health Nutr. 2001;4:647-657.

13. Palou A, Bonet ML. Challenges in obesity research. Nutr Hosp. 2013;28:144-153.

14. Agyemang C, Beune E, Meeks K, et al. Rationale and cross-sectional study design of the Research on Obesity and type 2 Diabetes among African Migrants: the RODAM study. BMJ Open. 2014;4: e004877.

15. Fox-Wasylyshyn SM, El-Masri MM. Handling missing data in self-report measures. Res Nurs Health. 2005;28:488495.

16. Ghana Statistical Service, Ghana Health Service, ICF Macro. Ghana Demographic and Health Survey 2008. Accra, Ghana: Ghana Health Service; 2009. https:// www.dhsprogram.com/pubs/pdf/ FR221/FR221\%5B13Aug2012\%5D. pdf. Accessed October 1, 2018.

17. Agyemang C, Nicolaou M, Boateng L, Dijkshoorn H, van de Born BJ, Stronks K. Prevalence, awareness, treatment, and control of hypertension among Ghanaian population in Amsterdam, The Netherlands: the GHAIA study. Eur J Prev Cardiol. 2013;20: 938-946.

18. Frank LK, Kröger J, Schulze MB, Bedu-Addo G, Mockenhaupt FP, Danquah I. Dietary patterns in urban Ghana and risk of type 2 diabetes. $\mathrm{Br} J$ Nutr. 2014;112:89-98.

19. Zeba AN, Delisle HF, Renier G. Dietary patterns and physical inactivity, two contributing factors to the double burden of malnutrition among adults in 
Burkina Faso, West Africa. J Nutr Sci. 2014;3:e50.

20. Cade J, Thompson R, Burley V, Warm D. Development, validation and utilisation of food-frequency questionnaires a review. Public Health Nutr. 2002;5: 567-587.

21. Michels KB, Welch AA, Luben R, Bingham SA, Day NE. Measurement of fruit and vegetable consumption with diet questionnaires and implications for analyses and interpretation. Am J Epidemiol. 2005;161:987-994.

22. Rosner B, Gore R. Measurement error correction in nutritional epidemiology based on individual foods, with application to the relation of diet to breast cancer. Am J Epidemiol. 2001;154: 827-835.

23. Matsudaira T. Measures of psychological acculturation: a review. Transcult Psychiatry. 2006;43:462-487.

24. Sayegh L, Lasry JC. Immigrants' adaptation in Canada: assimilation, acculturation, and orthogonal cultural identification. Can Psychol. 1993;34:98-109.

25. Berry JW. Immigration, acculturation, and adaptation. Appl Psychol. 1997;46:534

26. Méjean C, Traissac P, Eymard-Duvernay S, El Ati J, Delpeuch F, Maire B. Diet quality of North African migrants in France partly explains their lower prevalence of diet-related chronic conditions relative to their native French peers. J Nutr. 2007;137:2106-2113.

27. Pietzek T. A Ghanaian myth: fat is healthy and seductive! A qualitative survey about dietary habits among Ghanaians living in Berlin [in German]. Berlin, Germany: Hochschule Berlin University of Applied Sciences; 2012.

28. Gilbert PA, Khokhar S. Changing dietary habits of ethnic groups in Europe and implications for health. Nutr Rev. 2008;66:203-215.

29. Kassam-Khamis T, Judd PA, Thomas JE. Frequency of consumption and nutrient composition of composite dishes commonly consumed in the UK by South Asian Muslims originating from Bangladesh, Pakistan and East Africa (Ismailis). J Hum Nutr Diet. 2000;13:185-196.

30. Kohinor MJ, Stronks K, Nicolaou M, Haafkens JA. Considerations affecting dietary behaviour of immigrants with type 2 diabetes: a qualitative study among Surinamese in the Netherlands. Ethn Health. 2011;16:245-258.

31. Nicolaou M, Doak CM, van Dam RM, Brug J, Stronks K, Seidell JC. Cultural and social influences on food consumption in Dutch residents of Turkish and Moroccan origin: a qualitative study. J Nutr Educ Behav. 2009;41:232-241.

32. Osei-Kwasi HA, Powell K, Nicolaou M, Holdsworth M. The influence of migration on dietary practices of Ghanaians living in the United Kingdom: a qualitative study. Ann Hum Biol. 2017;44:454-463.

33. Hendriks AM, Gubbels JS, Jansen MW, Kremers SP. Health beliefs regarding dietary behavior and physical activity of Surinamese immigrants of Indian descent in the Netherlands: a qualitative study. ISRN Obes. 2012;2012:903868.

34. Tuomainen HM. Ethnic identity, (post) colonialism and foodways: Ghanaians in London. Food Cult Soc. 2009;12: 525-554.

35. Lee SK, Sobal J, Frongillo EA Jr. Acculturation, food consumption, and diet-related factors among Korean Americans. J Nutr Educ. 1999;31:321330.

36. Lv N, Cason KL. Dietary pattern change and acculturation of Chinese Americans in Pennsylvania. J Am Diet Assoc. 2004;104:771-778.

37. Hunt LM, Schneider S, Comer B. Should "acculturation" be a variable in health research? A critical review of research on US Hispanics. Soc Sci Med. 2004;59:973-986.

38. Lawrence JM, Devlin E, Macaskill S, et al. Factors that affect the food choices made by girls and young women, from minority ethnic groups, living in the UK. J Hum Nutr Diet. 2007;20:311319.

39. Vargas P, Jurado LF. Dietary acculturation among Filipino Americans. Int J Environ Res Public Health. 2015;13. ijerph13010016.

40. Mellin-Olsen T, Wandel M. Changes in food habits among Pakistani immigrant women in Oslo, Norway. Ethn Health. 2005; 10:311-339.

41. Osei-Kwasi HA. An Exploration of Dietary Practices and Associated Factors Amongst Ghanaians Living in Europe [thesis]. England: University of Sheffield; 2018.

42. Terragni L, Garnweidner LM, Pettersen KS, Mosdøl A. Migration as a turning point in food habits: the early phase of dietary acculturation among women from South Asian, African, and Middle Eastern countries living in Norway. Ecol Food Nutr. 2014;53:273-291.

43. Škreblin L, Sujoldžić A. Acculturation process and its effects on dietary habits, nutritional behavior and body-image in adolescents. Coll Antropol. 2003;27:469477.

44. Jamal A. Acculturation: the symbolism of ethnic eating among contemporary British consumers. Br Food J. 1996;98:12-26.

45. Cardona ET. Re-encountering Cuban tastes in Australia. Aust $J$ Anthropol. 2004;15:40-53

46. Midgley G. Systemic intervention for public health. Am J Public Health. 2006;96:466-472.

47. Holdsworth M, Nicolaou M, Langøien LJ, et al. Developing a systems-based framework of the factors influencing dietary and physical activity behaviours in ethnic minority populations living in Europe - a DEDIPAC study. Int J Behav Nutr Phys Act. 2017;14:154. 